\title{
Low cycle fatigue behavior and microstructure of a high alloyed metastable austenitic cast TRIP-steel
}

\author{
A. Glage ${ }^{\mathrm{a}}$, A. Weidner, T. Richter, P. Trubitz, and H. Biermann \\ Institute for Materials Engineering, Technische Universität Bergakademie Freiberg, Germany
}

\begin{abstract}
Total strain-controlled low-cycle fatigue tests were performed at room temperature on a high alloyed metastable austenitic stainless cast steel in the range of $1 \times 10^{-3} \leq \Delta \epsilon_{t} / 2 \leq 3 \times 10^{-2}$ at constant strain rate of $4 \times 10^{-3} \mathrm{~s}^{-1}$. The cyclic stress response revealed combinations of cyclic hardening, saturation and cyclic softening, depending on the applied cyclic total strain amplitude. Total strain amplitudes higher than $8 \times 10^{-3}$ result in a pronounced secondary hardening up to fracture. In the case of metastable austenitic steels, at higher strain amplitudes the secondary hardening is an indicator for the austenitic-martensitic transformation. The deformation-induced $\alpha^{\prime}$-martensite content was detected using a nondestructive magnetic measuring technique (feritscope). The microstructure was investigated for different total strain amplitudes applying optical and scanning electron microscopy (SEM). It could be observed that with an increasing total strain amplitude the deformation band density increased considerably.
\end{abstract}

\section{Introduction}

Recently, considerable research has been undertaken on the development and improvement of light-weight metallic materials in order to design more energy efficient structures with high safety requirements, which in turn involves an increase of the specific strength of the respective material. High alloyed metastable austenitic stainless cast steels belong to the class of TRIP/TWIP steels and are excellent candidates for this purpose due to their exceptional mechanical characteristics in terms of high specific strength and high ductility. During deformation, these steels can exhibit two mechanisms of strain hardening: martensitic transformation, also known as transformation-induced plasticity (TRIP), or twinning, which is referred as twinninginduced plasticity [1]. The strain-induced martensitic transformation in metastable austenitic stainless steels, such as AISI 304 and 321, is a well studied phenomenon under monotonic [2-4] and under cyclic loading [5-12]. The investigations revealed a considerable difference in the fatigue life between the strain-controlled and stress-controlled tests. In the stress-controlled tests the martensitic transformation increases the fatigue life as a result of the increasing strength and thus reduced deformation. Conversely, in strain-controlled tests the martensitic transformation results in a shorter fatigue life, caused by the strain hardening. Additionally, it was found that the onset of the deformation-induced martensitic transformation depends on the plastic strain amplitude and accumulated strain. For instance, in the case of the austenitic steel AISI 304L, the threshold of the plastic strain amplitude was determined to be approximately $0,3 \%[5]$.

In contrast to the metastable austenitic stainless steels, detailed investigations of the cyclic deformation behavior of metastable austenitic cast steels, which were developed recently [13, 14], are still missing. Thus, the present study was undertaken to analyze the cyclic deformation behavior of a variant of the austenitic cast steel. The strain amplitude dependence of

\footnotetext{
a e-mail: glage@ww.tu-freiberg.de
} 
microstructures and a possible deformation-induced martensite transformation is of particular interest in this study.

\section{Experimental details}

\subsection{Materials}

The material under consideration is a high alloyed metastable austenitic cast TRIP-steel with the following chemical composition in wt.\%: C-0.07, Cr-15.91, Ni-7.65, Mn-6.58, Si-0.85, Al$0.07, \mathrm{~N}-0.07$ and Fe-balance. The test material in terms of cast plates was solution annealed in vacuum at $1050{ }^{\circ} \mathrm{C}$ for 1 hour, water quenched and subsequently machined into cylindrical fatigue specimens. The microstructure of the material is presented in Fig. 1. The dendritic microstructure is characterized by coarse elongated grains, caused by the cast production route with grain sizes in the range of $160-740 \mu \mathrm{m}$. A few annealing twins and small amounts of $\mathrm{MnS}$ and $\delta$-ferrite were also detected.

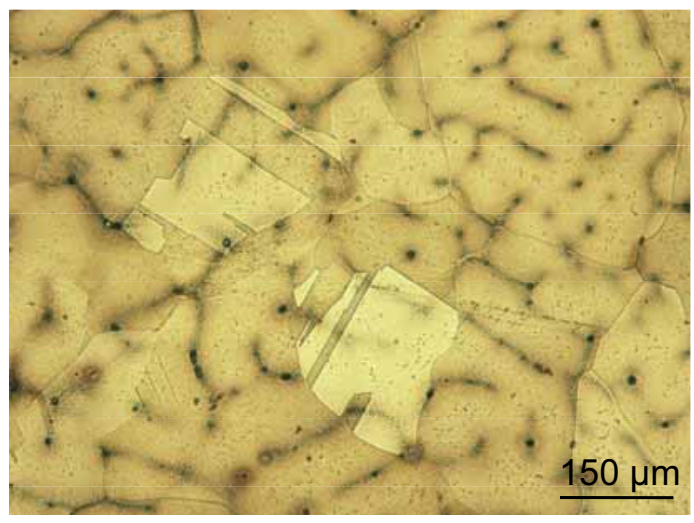

Fig. 1. Optical micrograph of the cast steel in the as heat-treated condition.

The monotonic tensile properties are summarized in Table 1. The significant difference between the yield strength and ultimate tensile strength indicates that the material exhibits a high amount of work hardening during monotonic tensile deformation.

Table 1. Mechanical properties of the austenitic cast steel.

\begin{tabular}{lc}
\hline $0.2 \%$ yield strength, $\sigma_{y s}$ & $263 \mathrm{MPa}$ \\
Ultimate tensile strength, $\sigma_{U T S}$ & $594 \mathrm{MPa}$ \\
Elongation at fracture, A & $63 \%$ \\
Young's modulus, E & $191 \mathrm{GPa}$ \\
\hline
\end{tabular}

\subsection{Experimental techniques}

The axial low cycle fatigue tests were carried out on a $100 \mathrm{kN}$ servohydraulic testing system (MTS 810) under total strain control with a strain-ratio of $R_{\epsilon}=-1$ and a constant strain rate of $4 \times 10^{-3} \mathrm{~s}^{-1}$ using triangular load-time functions at ambient temperature. Cylindrical specimens having a gauge diameter of $8 \mathrm{~mm}$ and a gauge length of $14 \mathrm{~mm}$ were electropolished prior to cyclic loading. The total strain amplitude $\Delta \epsilon_{t} / 2$ was varied between $1 \times 10^{-3}$ and $3 \times 10^{-2}$. A 
clip-on extensometer was applied to measure the strain and the tests were performed until the specimens failed. For microstructural observations in the SEM the specimens were cut parallel to the loading axis and were carefully prepared by grinding and final electropolishing. The observations were carried out in a FE-SEM (LEO 1530) which was equipped with a retractable four-quadrant BSE (backscattered electron)-detector. High-resolution images visualizing the dislocation structure were obtained using the ECCI (electron channelling contrast imaging) technique [15-17] in a FE-SEM (Ultra55, TU Dresden - Institute of Structural Physics, TU Bergakademie - Institute of Iron and Steel Research) which was equipped with an additional high-current mode and a BSE-detector mounted directly at the pole piece of the optical column. The high-current mode leads to probe currents of about $20 \mathrm{nA}$ using an acceleration voltage of $20 \mathrm{kV}$ and an aperture of $120 \mu \mathrm{m}$. In the LEO1530 without high-current mode and same aperture/acceleration voltage the probe current amounts only about 4-5 nA. EBSD-measurements were carried out in order to investigate the phase transformation of the TRIP steel from fcc austenitic phase into the bcc $\alpha$ '-martensite phase using HKL-technology from Oxford Instruments.

The deformation-induced ferromagnetic $\alpha^{\prime}$-martensite in the austenitic matrix $(\gamma)$ can be measured by magnetic permeability methods. For this purpose a commercially available measuring device (Fischer Feritscope) was applied. This instrument was calibrated accurately with four standards of known ferrite content. At least five measurements were performed on each sample at arbitrary locations on the specimen surface, situated distant from the fatigue crack. According to investigations of Talonen et al. [18], the feritscope readings F can be correlated to the $\alpha^{\prime}$-martensite contents by using a conversion factor of 1.7 .

\section{Results}

\subsection{Low cycle fatigue behavior}

Fig. 2 a) shows the cyclic deformation curves of the TRIP cast steel at different total strain amplitudes. The cyclic stress response depends strongly on the applied total strain level and can be generally classified into the following three cases. At total strain amplitudes lower than $8 \times 10^{-3}$, the material displayed an initial hardening followed by a very small softening, and then nearly saturation up to the final fracture. The initial hardening is caused by an increase of the dislocation density. Cyclic softening takes place when the annihilation rate of the dislocations exceeds their generation rate, inducing a net reduction of the dislocation density, or when the dislocations rearrange in a cell structure, resulting in an increased mean free path of dislocations $[19,20]$. Strain amplitudes of $8 \times 10^{-3}<\Delta \epsilon_{t} / 2<1.4 \times 10^{-2}$ result in an initial hardening followed again by a small softening or nearly saturation level and then a pronounced secondary hardening, which occurs up to the final failure. This secondary hardening was also observed in metastable austenitic steels, such as AISI 304L [5,21], and is attributed to an increasing volume fraction of $\alpha^{\prime}$-martensite during cyclic plastic deformation. Finally, at strain amplitudes $\Delta \epsilon_{t} / 2 \geq 1.4 \times 10^{-2}$ the cyclic stress response revealed very rapid strain hardening without reaching a level of saturation until the final fracture. It has to be pointed out that the stress amplitude at the higher strain amplitudes reached values close to the ultimate tensile strength. These results are in good agreement with the results of previous investigations performed on the wrought metastable austenitic steels AISI 304 and AISI 304L [5,11,21].

In order to compare the relative amount of initial hardening, taking place at the different total strain amplitudes, the degree of hardening can be calculated with the following equation:

$$
H=\frac{\sigma_{a}^{s a t}-\sigma_{a}^{1}}{\sigma_{a}^{1}}
$$

where $\sigma_{a}^{\text {sat }}$ and $\sigma_{a}^{1}$ are the stress amplitude at the half life time and at the first cycle, respectively. As can be seen in Fig. 2 b), the strain hardening increases with increasing applied strain amplitude, as also observed in conventional austenitic stainless steels, such as AISI 304L, AISI 316 and SUS304-HP [22]. Furthermore, a small reduction of the mean stress $\sigma_{m}$, taken at 

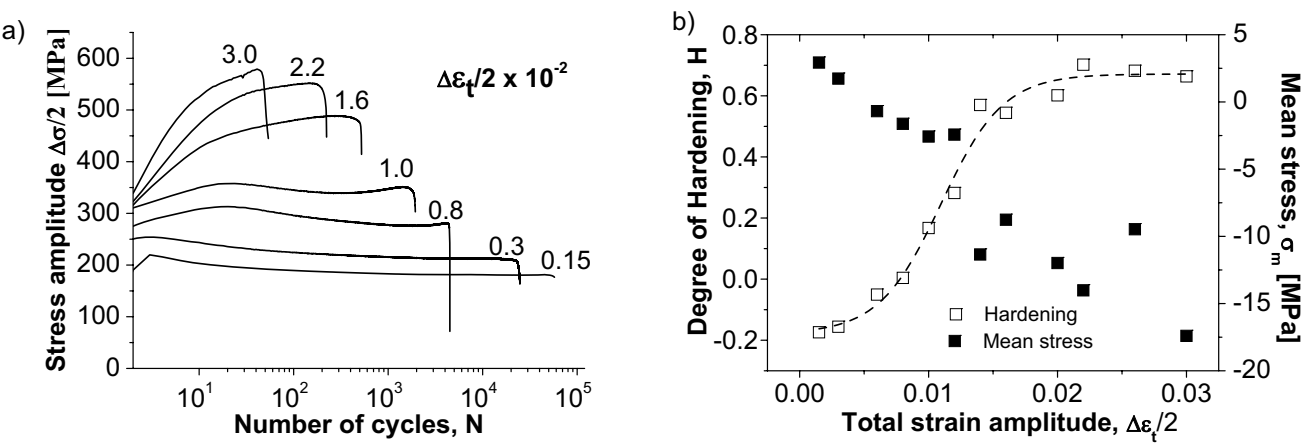

Fig. 2. a) Cyclic deformation curves at different total strain amplitudes. b) Degree of cyclic hardening $\mathrm{H}$ and mean stress as a function of total strain amplitude.

the half number of cycles to failure, can be observed with increasing total strain amplitude. This behavior can probably be attributed to the larger specific volume of the $\alpha$ '-martensite compared to the austenite, since the development of the mean stress can be an indirect possibility to quantify the transformed fraction of austenite [6].

The relation between the applied total strain amplitude and the number of reversals to failure $\left(2 \mathrm{~N}_{f}\right)$ was analyzed on the basis of the strain-life relationship stated by Basquin and Manson-Coffin. The expression for this relation is:

$$
\Delta \epsilon_{t} / 2=\Delta \epsilon_{e} / 2+\Delta \epsilon_{p} / 2=\frac{\sigma_{f}^{\prime}}{E}\left(2 N_{f}\right)^{b}+\epsilon_{f}^{\prime}\left(2 N_{f}\right)^{c}
$$

where $\sigma_{f}^{\prime}, \mathrm{b}, \epsilon_{f}^{\prime}$ and c are the fatigue strength coefficient, fatigue strength exponent, fatigue ductility coefficient and fatigue ductility exponent, respectively. The test data of the cast steel compared to a conventional AISI 304 are plotted in Fig. 3 a) and the parameters of both materials are summarized in Table 2. As can be seen, the elastic and plastic data follow the laws of Basquin and Manson-Coffin, respectively. Thus, Eq. (2) is a suitable approach to determine the fatigue life of the present material. However, the test data scatter in a wide range caused by the inhomogeneous cast microstructure. The comparison between the cast steel and AISI 304 reveals that at higher strain amplitudes the low cycle fatigue behavior is almost similar. Conversely, at lower strain amplitudes the cast steel shows shorter fatigue lives, induced by the inhomogeneous cast structure with stress concentrations in terms of micro pores and segregations. The lower transition fatigue life (i.e. the life where the total strain amplitude consists of equal elastic and plastic parts) of the TRIP cast steel $(\mathrm{N} \approx 23700)$ compared to AISI 304 $(\mathrm{N} \approx 38100)$ accounts also for an increased sensitivity to notches and internal defects [23].

Table 2. Parameters of the Basquin, Manson-Coffin and Ramberg-Osgood relationships, respectively.

\begin{tabular}{lccccccc}
\hline Material & $\sigma_{f}^{\prime}$ & $\epsilon_{f}^{\prime}$ & $\mathrm{b}$ & $\mathrm{c}$ & & $\mathrm{n}^{\prime}$ & $\mathrm{K}$ \\
\hline \hline Cast steel & 1668 & 1.05 & -0.19 & -0.63 & I. & 0.071 & 329 \\
& & & & & II. & 0.592 & 5870 \\
& & & & & III. & 0.304 & 1805 \\
AISI 304 [24] & 956 & 0.187 & -0.11 & -0.46 & & 0.29 & 1870 \\
\hline
\end{tabular}

Fig. 3 b) shows the cyclic stress-strain curve compared to the monotonic stress-strain curve. It can be observed that the material exhibits cyclic strain softening at lower strain amplitudes $\left(\epsilon_{p}<0.58 \%\right)$ and pronounced cyclic hardening at higher strain amplitudes. The experimental data were fitted with the Ramberg-Osgood equation using the least squares technique. 
a)

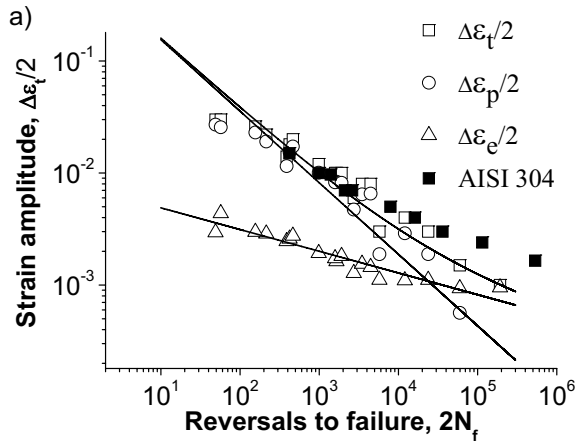

b)

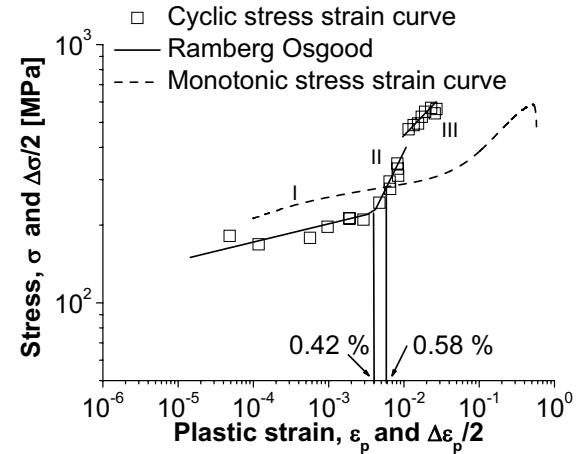

Fig. 3. a) Manson-Coffin and Basquin relations for the TRIP cast steel compared to AISI 304 [24]. b) Cyclic stress-strain curve compared to the monotonic stress-strain curve.

$$
\Delta \sigma / 2=K^{\prime}\left(\frac{\Delta \epsilon_{p}}{2}\right)^{n^{\prime}}
$$

As can be seen, the cyclic stress-strain curve can be divided into three linear regions with different values of $\mathrm{K}^{\prime}$ and n', which are summarized in Table 2. At low strain amplitudes $\left(\epsilon_{p} \leq 0.42 \%\right)$ the slope n' is similar to the one occurring in the monotonic tensile test. Conversely, at intermediate strain amplitudes $\left(0.42 \%<\epsilon_{p} \leq 0.8 \%\right)$ the slope is exceptionally high $\left(\mathrm{n}^{\prime} \approx 0.59\right)$, implying a considerable cyclic hardening. In the third region the capacity of cyclic hardening decreases slightly. Thus, it can be deducted that the cyclic hardening converges to a saturation state. Comparable results concerning the three different regions in the cyclic stressstrain curve were also be observed by Baudry et al. [25] for a Fe-18Cr-6.5Ni-0.19C stainless steel.

\subsection{Deformation microstructure}

Fig. 4 shows SEM micrographs of specimens deformed at total strain amplitudes of $6 \times 10^{-3}$ (a), $1.2 \times 10^{-2}$ (b) and $2.6 \times 10^{-2}$ (c). It becomes evident that the density of deformation bands is increasing with increasing total strain amplitudes. At low strain amplitudes the grains contain few individual deformation bands on maximally two activated slip planes. At medium strain amplitudes the deformation bands become thicker and more slip planes are activated. At high strain amplitudes only at several places individual deformation bands can be distinguished. The microstructure shows a lot of local distortions.

High-resolution ECC-images of the developed dislocation microstructure were taken from specimens cycled at low and medium total strain amplitudes. The micrographs in Fig. 5 display a remarkable difference in the developed dislocation structures. Whereas Fig. 5 a) illustrates a well developed planar dislocation structure at low strain amplitudes, Fig. 5 b) shows a pronounced cell/wall structure of dislocation dense regions and dislocation free channels which is typical for wavy glide materials [26,27]. Furthermore, it becomes evident that both the density and the thickness of deformation bands increase with increasing total strain amplitude. In addition, Fig. $5 \mathrm{~b})$ demonstrates very well that the deformation bands consist of a lot of very fine lamellas. The thickness of these lamellas measured perpendicular to their length varies in a range $<50 \mathrm{~nm}$. Typical values are about $20 \mathrm{~nm}$.

In order to investigate the locations where the phase transformation from austenite to martensite takes place EBSD measurements were performed. Results of an EBSD-measurement on the above described lamellar structure of the deformation bands of a specimen cycled at total strain amplitude of $1.2 \times 10^{-2}$ are given in Fig. 6. The SEM micrograph in Fig. 6 a) taken with the BSE-detector at a working distance of $5 \mathrm{~mm}$ shows darker areas in a bright deformation band (marked by arrows). These darker areas are identical with places where the fcc austenitic 

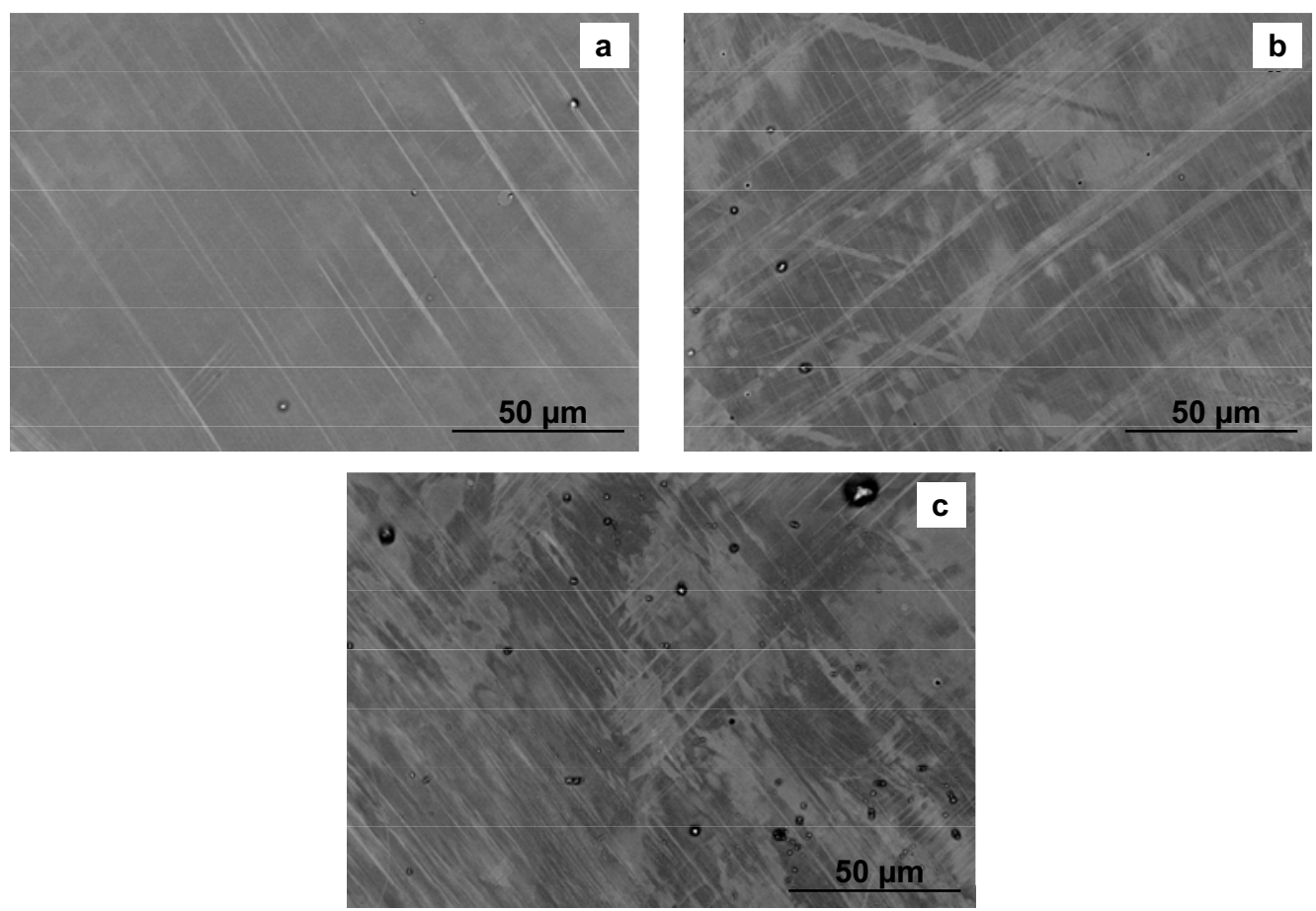

Fig. 4. SEM micrographs in BSE contrast showing the microstructure of the TRIP cast steel cycled to failure at different total strain amplitudes; (a) $\Delta \epsilon_{t} / 2=6 \times 10^{-3}$, (b) $\Delta \epsilon_{t} / 2=1.2 \times 10^{-2}$, (c) $\Delta \epsilon_{t} / 2=2.6 \times 10^{-2}$. Loading axis is horizontal.

phase (red color) was transformed into the bcc $\alpha^{\prime}$-martensitic phase (blue color), shown in Fig. $6 \mathrm{c})$. Furthermore, in Fig. $6 \mathrm{~b}$ ) it becomes visible that inside the deformation bands the band contrast of the Kikuchi pattern is always worse than in the matrix between the deformation bands which is caused by a high defect density. This is the reason for the high number of zero solutions inside these band structures.
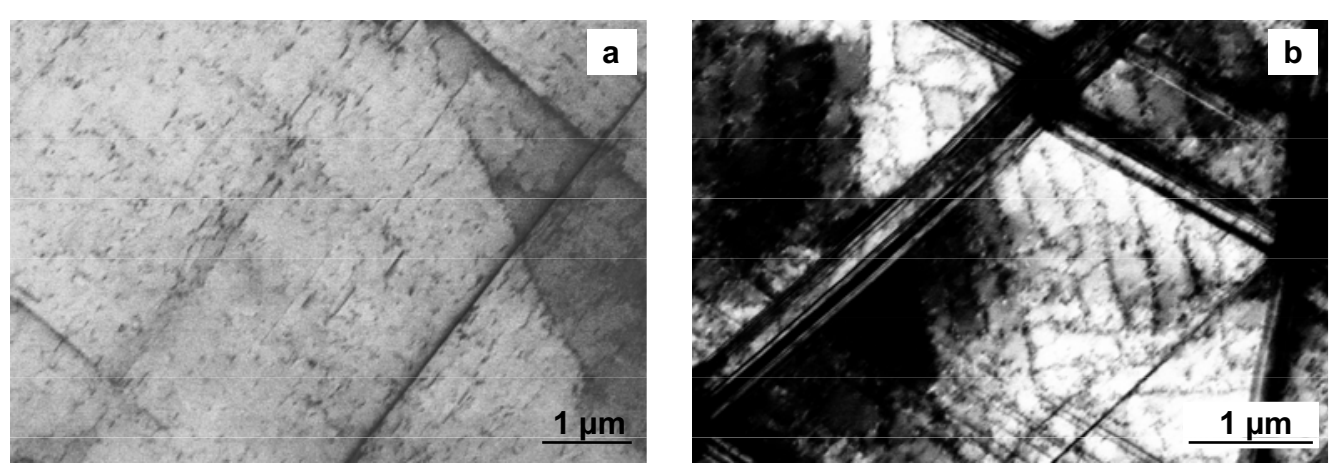

Fig. 5. ECC-images of the developed dislocation structure; (a) planar dislocation structure at low total strain amplitude $\left(\Delta \epsilon_{t} / 2=6 \times 10^{-3}\right)$, (b) deformation bands with lamellar structure and typical wavy dislocation glide structure with walls/cells between the deformation bands at medium total strain amplitude $\left(\Delta \epsilon_{t} / 2=1.2 \times 10^{-2}\right)$. Loading axis is horizontal.

Another important fact from these measurements is that the boundaries of the matrix and the deformation bands are quite often typical twin boundaries ( $\Sigma 3$, yellow color in Fig. $6 \mathrm{~b})$ 
and d)) characterized by a rotation of $60^{\circ}$ around an $<111>$ axis. In addition, this is correlated with an orientation change in the austenitic phase illustrated in Fig. $6 \mathrm{~d}$ ) by the green color inside the bands and the pink color for the matrix.

In austenitic steels, the plastic deformation cannot be performed only by gliding of perfect dislocations but also by the formation of hexagonal closed packed $\epsilon$-martensite or mechanical twinning depending on the stacking fault energy. These steels are so-called TRIP or TWIPsteels, respectively. Mechanical twinning as well as the formation of $\epsilon$-martensite is strongly correlated to the dissociation of perfect dislocations into partial dislocations producing stacking faults (SFs). According to Olson et al. [28], intrinsic and extrinsic stacking faults are responsible for the formation of mechanical twins and $\epsilon$-martensite. Quite recently, studies using a combination of EBSD and TEM-investigations on Fe-Mn-based austenitic steel [29] showed that extrinsic SFs were prior observed to the formation of $\epsilon$-martensite and intrinsic SFs were found when mechanical twinning takes place.
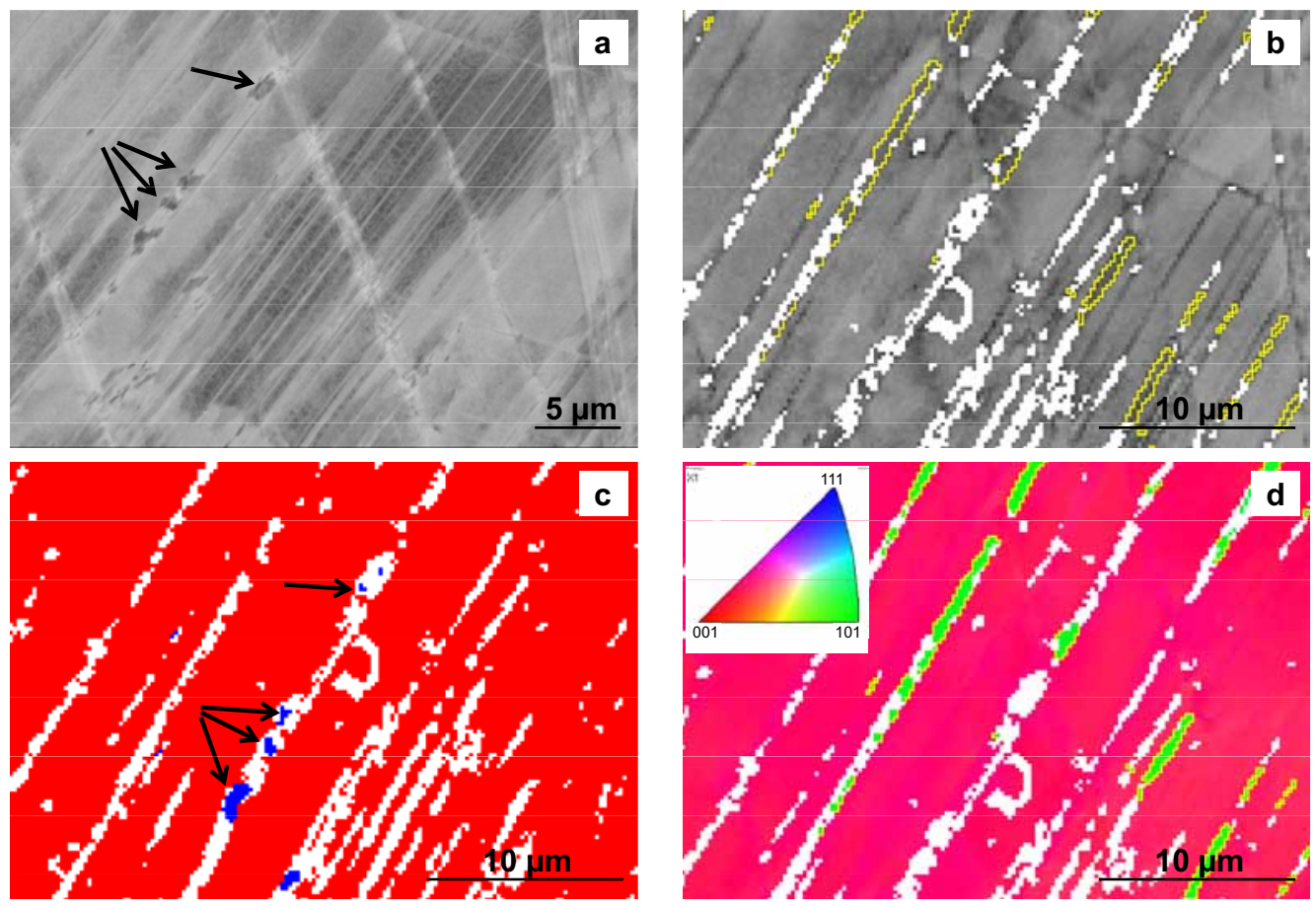

Fig. 6. Results of EBSD-measurements on a specimen deformed at a total strain amplitude of $\Delta \epsilon_{t} / 2=1.2 \times 10^{-2}$ (a) BSE-SEM-micrograph with lamellar deformation band structure and locations of phase transformation, (b) EBSD-map with band contrast and indicated twin boundaries (yellow lines), (c) EBSD-phase map - red color austenite, blue color $\alpha^{\prime}$-martensite, (d) EBSD-orientation map, colors with respect to the stereographic triangle given in the left upper corner. Please note: Zero solutions are indicated by white color. Loading axis is horizontal.

Combined with the knowledge based on literature research it seems to be apparent that the observed lamellar structure inside the deformation bands can be correlated with the formation of micro twins and/or stacking faults. The appearance of extrinsic and/or intrinsic SFs has to be studied in future by TEM investigations for this type of TRIP steels.

\section{3 $\alpha^{\prime}$-martensite formation}

The feritscope measurements revealed that the amount of $\alpha$ '-martensite of broken specimens increases with the total strain amplitude (Fig. 7). The martensitic transformation starts at 
a total strain amplitude of about $8 \times 10^{-3}-1.2 \times 10^{-2}$, which is in agreement with the secondary hardening observed at intermediate strain amplitudes. At lower strain amplitudes the density of defects and shear bands in the $\gamma$-phase which represent the nucleation sites for strain-induced martensite is too low, resulting in a stable austenitic structure. It is worth noting that the $\alpha^{\prime}$-martensite contents scatter in a wide range caused by the heterogenous cast microstructure combined with differences in the chemical composition. The maximum $\alpha$ '-martensite content of $\approx 5 \%$ at a total strain amplitude of $3 \times 10^{-2}$ is rather low, accounting for a high stability of the austenitic phase. Near to the crack tip the $\alpha$ '-martensite content reaches values up to $20 \%$ induced by the high localized plastic deformation.

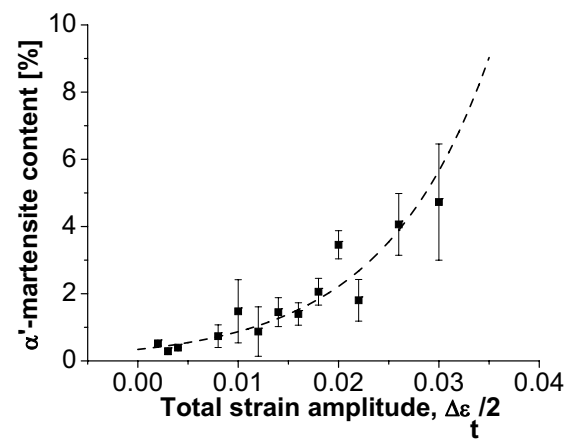

Fig. 7. Variation of $\alpha^{\prime}$-martensite content depending on the applied total strain amplitude.

\section{Conclusions}

In the current study the fatigue properties of a high alloyed metastable austenitic stainless cast steel were investigated. The cyclic deformation behavior revealed combinations of cyclic hardening, saturation and cyclic softening, depending on the applied cyclic total strain amplitude. The resulting cyclic stress-strain curve can be divided into three different regimes of cyclic plastic deformation caused by a differing microstructure. Low strain amplitudes result predominantly in a planar dislocation structure. Conversely, at high strain amplitudes cell/wall structures dominate. Furthermore, with increasing strain amplitude the amount of the lamellas inside the deformation bands increases, resulting in a remarkable cyclic hardening. In the present cast steel the content of deformation-induced $\alpha^{\prime}$-martensite is rather small, implying a high stability of the austenitic phase. In principle, the fatigue properties are similar to the behavior of wrought metastable stainless steels with the exception of a higher scatter in fatigue lives.

\section{Acknowledgment}

The authors thank Dr. E. Hieckmann from the Institute of Structural Physics of the TU Dresden and Dr. E. Niederschlag from the Institute of Iron and Steel Research of the TU Bergakademie Freiberg for providing their high-resolution scanning electron microscopes Ultra55 for the ECC investigations of the dislocation structures.

\section{References}

1. O. Grässel, L. Krüger, G. Frommeyer, L. W. Meyer: International Journal of Plasticity 16, (2000) 1391-1409. 
2. G.B. Olson, M. Cohen: Metallurgical Transactions A 6, (1975) 791-795.

3. W.J. Dan, S.H. Li, W.G. Zhang, Z.Q. Lin: Materials \& Design 29, (2008) 604-612.

4. K.H. Lo, C.H. Shek, J.K.L. Lai: Materials Science and Engineering 65, (2009) 39-104.

5. M. Bayerlein, H.-J. Christ, H. Mughrabi: Materials Science and Engineering A 114, (1989) L11-L16.

6. M. Bayerlein, H. Mughrabi, M. Kesten, B. Meie: Materials Science and Engineering A 159, (1992) $35-41$.

7. J. Kaleta, G. Zicetek: Materials Science and Engineering A 234, (1997) 680-683.

8. J. Kaleta, G. Zicetek: Fatigue \& Fracture of Engineering Materials \& Structures 21, (1998) 955-964.

9. R.G. Teteruk, H.J. Maier, H.-J. Christ: Low cycle fatigue and elasto-plastic behaviour of materials, (1998) 321-326.

10. M. Topic, R.B. Tait, C. Allen: International Journal of Fatigue 29, (2007) 656-665.

11. M. Smaga, F. Walther, D. Eifler: Materials Science and Engineering A 483-484, (2008) 394-397.

12. M. Grosse, D. Kalkhof, M. Niffenegger, L.Keller: Materials Science and Engineering A 437, (2006) 109-113.

13. A. Weiß, P.R. Scheller, H. Gutte: Nichtrostender austenitischer Stahlguss und seine Verwendung Patentanmeldung AZ 102006033973.

14. A. Jahn, A. Kovalev, A. Weiß, P.R. Scheller, S. Wolf, L. Krüger, S. Martin, U. Martin, D. Rafaja: Proc. ESOMAT 2009, Prague, September 2009.

15. A. Schwab, J. Bretschneider, C. Buque, C. Blochwitz, C. Holste: Phil. Mag. Letters 74, (1996) 449-454.

16. B.A. Simkin, B.C. Ng, M.A. Crimp: Microscopy and Analysis , (1999) 11-13.

17. A. Weidner, J. Man, W. Skrotzki, J. Polk: Proc. 12th Inter. Conf. on Fatigue (ICF12), Ottawa, July 2009.

18. J. Talonen, P. Aspegren and H. Hänninen: Materials Science and Technology 20, (2004) 1506-1512.

19. A.M. Sherman: Metallurgical Transactions A 6, (1975) 1035-1040.

20. H.-J. Crist, H. Mughrabi: Low cycle fatigue and elasto-plastic behaviour of materials, (1992).

21. U. Krupp, H. -J. Christ, P. Lezuo, H. J. Maier, R. G. Teteruk: Materials Science and Engineering A 319-321, (2001) $527-530$.

22. D. Ye, S. Matsuoka, N. Nagashima, N. Suzuki: Materials Science and Engineering A 415, (2006) 104-117.

23. S. Ganesh Sundara Raman, K. A. Padmanabhan: International Journal of Fatigue 18, (1996) 71-79.

24. A.Braun, unpublished research work (diploma thesis), University of Freiberg (2006).

25. G. Baudry, A. Pineau: Materials Science and Engineering 28, (1977) 229-242.

26. T. Kruml, J. Polák, K. Obrtlík, S. Degallaix: Acta Metallurgica 45, (1997) 5145-5151.

27. Y. Li, C. Laird: Materials Science and Engineering A186, (1994) 87-103.

28. G.B. Olson, M. Cohen: Metallurgical Transactions A 7, (1976) 1897.

29. H. Idrissi, L. Ryelandt, M. Veron, D. Schryvers, P.J. Jacques: Scrip. Mater. 60, (2009) 941-944.

30. G. Gottstein: Physikalische Grundlagen der Materialkunde, Springer Verlag, 2. Edition, (2001) 245. 